\title{
OLEGRANON FRAGTURE
}

\section{DR. MUHAMMAD INAM}

FCPS (Ortho)

Junior Registrar

Department of Orthopedic and Spine Surgery

PGMI Hayatabad Medical Complex Peshawar

\section{DR. ABDUL SATAR}

FCPS (Ortho)

Medical Officer

Department of Orthopedic and Spine Surgery

PGMI Hayatabad Medical Complex Peshawar
Dr. Mohammad Saeed, MD

Medical Officer

Department of Orthopedic and Spine Surgery

PGMI Hayatabad Medical Complex Peshawar

\author{
Dr. Mohammad Arif \\ FCPS (Ortho) \\ Associate Professor \\ Department of Orthopedic and Spine Surgery \\ PGMI Hayatabad Medical Complex Peshawar
}

\section{DR. WAQAR HASSAN}

FCPS (Ortho)

Medical Officer

Department of Orthopedic and Spine Surgery

PGMI Hayatabad Medical Complex Peshawar

ABSTRACT... Objective: The objective of the study is to assess the clinical and radiological outcome after tension band wiring of olecranon fractures. Design: Descriptive study. Setting: Department of Orthopedics and Spine Surgery, Hayatabad Medical Complex Peshawar. Period: July 2007 to June 2010. Materials and Methods: 29 consecutive patients of either sex with age above 20 years, having olecranon fracture. Fracture osteosynthesis was achieved with the insertion of two parallel $1.8 \mathrm{~mm}$ Kirschner wires from the tip of the olecranon and an $18 \mathrm{gauge}$ wire in a figure of eight fashion. Then functional outcome is evaluated with Mayo Elbow Performance score (MEPS) while radiological outcome is evaluated with standard radiographs. Results: Out of 29 patients, male were 19(65.5\%) while female were 10(34.5\%). Minimum age was 20 , maximum 80 and average age was 47.5 years. There were $7(24.1 \%)$ patients with type A, 6(20.7\%) type B, 9(31\%) type C, 6(20.7\%) type E and 1(3.4\%) with Schatzker type F fracture. Mayo Elbow Performance Score was Excellent in 13(44.8\%), Good in 10(34.5\%), Fair in 4(13.6\%) and Poor in 2(6.9\%) patients. There were 10(34.5\%) complications including prominent wire in 3(10.3\%), osteoarthritis in $1(3.4 \%)$, broken skin in $3(10.3 \%)$, irritation of skin in $1(3.4 \%)$, erythema in $1(3.4 \%)$ and serous discharge in $1(3.4 \%)$ patient. There was no non union recorded in this study. Conclusions: Olecranon fractures heal well in most instances achieving recovery of normal function in more than $95 \%$ of patients. Functional outcome is dependent on fracture severity, length of immobilization, and patient factors.

Key words: Tension Band Wire, Elbow Function, Mayo Elbow Performance Score, Olecranon

\section{INTRODUCTION}

Olecranon fractures are common injuries of the proximal ulna which constitute about $10 \%$ of all upper extremity lesions ${ }^{1}$. Despite the fact that the olecranon is a very heavy, strong process of bone, it is fractured rather frequently in adults. This is due partly to its exposed position on the point of the elbow, where most direct injuries to the elbow occur and partly to the tremendous cross strain put on the olecranon during falls on the flexed forearm. Most of the olecranon fractures are intra articular and isolated ${ }^{2}$.

The most common mechanism of an olecranon fracture is a fall on the semi flexed supinated forearm. The next most frequent cause of this injury is direct trauma, as in falls on or blows to the point of the elbow. Occasionally the olecranon may be fractured by hyperextension injuries, such as those resulting in elbow dislocation in adults or supracondylar fractures in children. Very rarely is the olecranon broken by muscular violence as in throwing ${ }^{3}$.

Due to the intra-articular extension of fractures, anatomic reduction and early mobilization should be achieved in any case 3 . It is known that only undisplaced fracture that is $5 \%$ of total, are treated conservatively while all displaced fractures are treated with open reduction internal fixation ${ }^{4}$.

There are different method for open reduction and 
internal fixation but tension band wiring (TBW) is most popular in this part of world which was introduced by Weber and Vasey ${ }^{5}$. However it is not free of complication. Infection, non-union, malunion and ulnar nerve palsy can be affects of operative treatment in up to $10 \%$ of cases ${ }^{6,7}$. Moreover, the subcutaneous placement of K-wires and their potential migration may be responsible for local pain, secondary displacement and wound healing problems ${ }^{8,9}$.

The purpose of this study was to assess the clinical and radiological outcome after tension band wiring of olecranon fractures.

\section{METHOD AND MATERIAL}

This descriptive study was performed in Department of Orthopedics and Spine Surgery, Hayatabad Medical Complex Peshawar from July 2007 to June 2010 on 29 consecutive patients of either sex with age above 20 years, having olecranon fracture.

All patients were selected from emergency department and admitted to ward. When the patients were stabilized then the purpose of the study was explained to them, their cooperation sought, their reservations and concerns were addressed and informed written consent was taken. Schatzker ${ }^{10}$ classification was used in this study which takes into account the fracture configuration as well as the stability of the elbow joint.

The surgical procedures were carried out with the patient in a lateral decubitus position under general anesthesia. A tourniquet was inflated after giving intravenous Cefuroxime 1.5 grams and the fracture site was approached via a posterior midline skin incision. Fracture osteosynthesis was achieved with the insertion of two parallel $1.8 \mathrm{~mm}$ Kirschner wires from the tip of the olecranon and an 18 gauge circlage wire in a figure of eight fashion. To avoid intra operative iatrogenic injury to anterior interosseous nerve we avoid the penetration of the ulnar anterior cortex. The proximal end of K-wires was bent and the cerclage wire was placed through a hole that was drilled transversely in the distal fragment. Subsequently, the cerclage wire was tightened to create interfragmentary compression. One knot technique of tightening was utilized.

The postoperative protocol included antibiotics administration (Cefuroxime) for 24 hours and progressive mobilization of the elbow joint. In all cases a posterior splint with the elbow in a semi flexed position was applied for a period of 2 weeks to prevent fracture displacement. At two weeks period the posterior splint and stitches were removed and active exercises were advised. Anteroposterior and lateral elbow radiographs were repeated at first post operative day, at fortnight, at 6 week and three months intervals until evidence of union was detected. At six months, radiographs were taken of fractured elbow, as well as of normal elbow for comparison, for evidence of osteoarthritis. Flexionextension of the elbow and pronation and supination of the forearm were measured with a goniometer. Patientrated outcomes evaluated with the Mayo Elbow Performance Score (MEPS) 11 (Figure 1). The duration of follow up was 1year. Hardware removal was done in symptomatic patients. The data was analyzed with the help of SPSS version 10.

\section{RESULTS}

There were total 29 patients in the study. Male patients were $19(65.5 \%)$ while female patients were 10(34.5\%). Minimum age was 20, maximum 80 and average age was 47.5 years. There were $7(24.1 \%)$ patients with type A, 6(20.7\%) type B, 9(31\%) type C, 6(20.7\%) type E and 1(3.4\%) with Schatzker type F fracture (Table I). Mayo Elbow Performance Score was Excellent in 13(44.8\%), Good in 10(34.5\%), Fair in 4(13.6\%) and Poor in 2(6.9\%) patients (Table II). There were 10(34.5\%) complications including prominent wire in $3(10.3 \%)$, osteoarthritis in $1(3.4 \%)$, broken skin in $3(10.3 \%)$, irritation of skin in $1(3.4 \%)$, erythema in $1(3.4 \%)$ and serous discharge in 1 (3.4\%) patient (Table III). There was no non union recorded in this study. In 9(31\%) patients hardware was symptomatic and was removed at 6 months period, while rest of the hardware is removed in one year average.

\section{DISCUSSION}

Fracture of Olecranon heals well when properly reduced and immobilized by tension band wire but it is not free of complications. Sometime there is subjective complaints and loss of function in activities of daily life which necessitate metal removal ${ }^{7}$. There are some prognostic 


\begin{tabular}{|c|c|c|c|}
\hline \multicolumn{4}{|c|}{ Mayo elbow performance score (MEPS) ${ }^{11}$} \\
\hline \multicolumn{3}{|c|}{ Section - 1 Pain Intensity } & 45 \\
\hline \multirow{4}{*}{\multicolumn{3}{|c|}{$\begin{array}{l}\text { None } \\
\text { Mild } \\
\text { Moderate } \\
\text { Severe }\end{array}$}} & 45 \\
\hline & & & 30 \\
\hline & & & 15 \\
\hline & & & - \\
\hline \multicolumn{3}{|l|}{ Section - 2 Motion } & 20 \\
\hline \multirow{3}{*}{\multicolumn{3}{|c|}{$\begin{array}{l}\text { Arc of motion greater than } 100 \text { degrees } \\
\text { Arc of motion between } 50 \text { and } 100 \text { degrees } \\
\text { Arc of motion less than } 50 \text { degrees }\end{array}$}} & 20 \\
\hline & & & 15 \\
\hline & & & 5 \\
\hline \multicolumn{3}{|c|}{ Section - 3 Stability } & 10 \\
\hline \multirow{3}{*}{\multicolumn{3}{|c|}{$\begin{array}{l}\text { Stable } \\
\text { Moderate instability } \\
\text { Grossly Unstable }\end{array}$}} & 10 \\
\hline & & & 5 \\
\hline & & & - \\
\hline \multicolumn{3}{|c|}{ Section 4 - Function (Tick as many as able) } & 25 \\
\hline \multirow{5}{*}{\multicolumn{3}{|c|}{$\begin{array}{l}\text { Can comb hair } \\
\text { Can eat } \\
\text { Can perform hygiene } \\
\text { Can don shirt } \\
\text { Can don shoe }\end{array}$}} & 5 \\
\hline & & & 5 \\
\hline & & & 5 \\
\hline & & & 5 \\
\hline & & & 5 \\
\hline \multicolumn{3}{|l|}{ Total } & 100 \\
\hline \multicolumn{4}{|c|}{ Fig-1. Interpreting the Mayo Elbow Performance Score } \\
\hline \multirow{2}{*}{$\begin{array}{l}\text { Score greater } \\
\text { than } 90 \\
\text { Excellent }\end{array}$} & Score 75-89 & Score $60-74$ & $\begin{array}{c}\text { Score } \\
\text { below } 60\end{array}$ \\
\hline & Good & Fair & Poor \\
\hline \multicolumn{4}{|c|}{ Table-I. Schatzker classification $(n=29)$} \\
\hline Type & Frequency & & \%age \\
\hline$A$ & 07 & & 24.1 \\
\hline B & 06 & & 20.7 \\
\hline C & 09 & & 31.0 \\
\hline$E$ & 06 & & 20.7 \\
\hline $\mathrm{F}$ & 01 & & 3.4 \\
\hline Total & 29 & & 100.0 \\
\hline
\end{tabular}

factors like primary elbow instability and fracture morphology that affect elbow function and development
Table-Il. Mayo elbow performance score $(n=29)$

$\begin{array}{ccc}\text { Grade } & \text { Frequency } & \text { \%age } \\ \text { Excellent } & 13 & 44.8 \\ \text { Good } & 10 & 34.5 \\ \text { Fair } & 04 & 13.8 \\ \text { Poor } & 02 & 6.9 \\ \text { Total } & 29 & 100.0\end{array}$

\begin{tabular}{lcc}
\multicolumn{3}{c}{ Table-lll. Complications $(\mathrm{n}=2 \mathrm{29})$} \\
& Frequency & \%age \\
No complication & 19 & 65.6 \\
Osteoarthritis & 01 & 3.4 \\
Irritation of skin & 01 & 3.4 \\
Prominent TBW & 03 & 10.3 \\
Serous discharge & 01 & 3.4 \\
Skin broken down & 03 & 10.3 \\
Superficial erythema & 01 & 3.4 \\
Total & 29 & 100.0
\end{tabular}

of osteoarthritis after operative treatment of olecranon fractures ${ }^{8}$.

The most frequent complication that was noted in Macko et $\mathrm{al}^{12}$ study was symptomatic prominence of the Kirschner wires at the elbow in sixteen out of twenty patients which was $3(10.3 \%)$ in our study ${ }^{12}$. There was skin breakdown in four patients, and infection developed in one while in our study skin breakdown in $3(10.3 \%)$ and erythema was noticed in 1(3.4\%). Measurable proximal migration of the Kirschner wires, however, occurred in only three patients ${ }^{12}$.

In Karlsson MK et al ${ }^{13}$ study, eighty four percent of the 73 patients had no complaints at follow up, $12 \%$ had occasional pain, and $4 \%$ had daily pain. In their study ninety six percent had an excellent or good outcome while in our study outcome was excellent in 13(44.8\%) and good in 10(34.5\%) patients. Radiographic signs of 
degenerative changes were found in more than $50 \%$ of the fractured elbows. Radiographic signs of osteoarthritis were found in $6 \%$ of the formerly fractured elbows, of which only two patients had a poor outcome while in our study only $1(3.4 \%)$ patient had osteoarthritis with 2(6.9\%) poor outcome.

In their study Rommens et al ${ }^{14}$ analyzed the fracture type, fracture classification, associated lesions, technical correctness of osteosynthesis, age and comorbidity. They also evaluated radiological end result (intraarticular steps, gaps, arthrosis), subjective complaints, mobility of the elbow joint and muscle strength. Patients with an unstable elbow had a higher loss of elbow function than others. There was a correlation between fracture morphology and osteoarthritis.

Villanueva et $\left.a\right|^{15}$ studied 37 consecutive patients that were followed up for 4 years. According to the Mayo Elbow Performance Score, the results were graded as good or excellent in $32(86 \%)$ patients, while in our study outcome was excellent in 13(44.8\%) and good in $10(34.5 \%)$ patients. In 10 patients, degenerative changes developed ${ }^{15}$ while in our study only 1 (3.4\%) patient had arthritic changes. Arthritic changes were significantly associated with elbow instability and were more common in the presence of associated radial head or coronoid fractures. In their study symptomatic hardware removal was required in 17 cases $^{15}$.

Anani et $a{ }^{16}$ studied 63 patients in which wound infection developed in 6(9.5\%) patients while in our study only one patient had developed erythema. No nonunion, malunion or ulnar nerve palsies was recorded in their study which is almost comparable to our study ${ }^{16}$. Hardware removal was recorded in $45(71.4 \%)$ patients due to pin prominence or localized pain. Twenty nine (46\%) patients had an excellent functional result while four $(6.4 \%)$ had poor result while in our study $13(44.8 \%)$ had excellent and $2(6.9 \%)$ patients had poor outcome results. The poor results were significantly associated with fracture type and the duration of immobilization ${ }^{16}$.

\section{CONCLUSIONS}

Tension-band wiring provides satisfactory results in a high percentage of olecranon fractures. However, the outcome may be compromised in the presence of elbow instability and associated fractures of the radial head and coronoid. Functional outcome is dependent on fracture severity, length of immobilization, and patient factors. Symptomatic hardware requiring removal is the most frequent complication.

Copyright(C) 30 May, 2012.

\section{REFERENCES}

1. Newman SD, Mauffrey C, Krikler S. Olecranon fractures. Injury. 2009;40(6):575-81.

2. Rommens PM, Schneider RU, Reuter M. Functional results after operative treatment of olecranon fractures. Acta Chir Belg. 2004;104(2):191-7.

3. lannuzzi N, Dahners L. Excision and advancement in the treatment of comminuted olecranon fractures. J Orthop Trauma. Mar 2009;23(3):226-8.

4. Gartsman GM, Sculco TP, Otis JC. Operative treatment of olecranon fractures. Excision or open reduction with internal fixation. J Bone Joint Surg Am. Jun 1981;63(5):718-21.

5. Weber BG, Vasey H: Osteosynthesis in Olecranon Fractures. ZUnfallmed Berufskr 1963, 56:90-96.

6. Murphy DF, Greene WB, Dameron TB Jr. Displaced olecranon fractures in adults. Clinical evaluation. Clin Orthop. 1987;224:215-23.

7. Sultan S, Khan AZ. Management of comminuted fractures of the olecranon by tension band wiring. $J$ Ayub Med Coll Abbottabad. 2003;15(3):27-9.

8. Veillette CJ, Steinmann SP. Olecranon fractures. Orthop Clin North Am. 2008;39 (2): 229-36.

9. Erturer RE, Sever C, Sonmez MM, Ozcelik IB, Akman S, Ozturk I. Results of open reduction and plate osteosynthesis in comminuted fracture of the Olecranon. J Shoulder Elbow Surg. 2011;20(3):449-54.

10. Schatzker J. Fractures of the olecranon. In: The Rationale of Operative Fracture Care. Berlin, Germany: Springer-Verlag; 1991.

11. Morrey BF, An KN. Functional evaluation of the elbow. In: Morrey BF, editor. The elbow and its disorders. 3rd ed. Philadelphia:WB Saunders; 2000. p 82.

12. Macko D, Szabo RM. Complications of tension-band 
wiring of Olecranon. J Bone Joint Surg Am. 1985 Dec;67(9):1396-401.

13. Karlsson MK, Hasserius R, Karlsson C, Besjakov J, Josefsson PO. Fractures of the olecranon: a 15 to 25year follow up of 73 patients. Clin Orthop Relat Res. 2002;403:205-12.

14. Rommens PM, Kuchle R, Schneider RU. Olecranon fractures in adults: factors influencing outcome.Injury. 2004;35(11):1149-57.
15. Villanueva P, Osorio F, Commessatti M, Sanchez-Sotelo $J$. Tension-band wiring for olecranon fractures: Analysis of risk factors for failure. J Shoulder Elbow Surg. 2006;15(3):351-56.

16. Anani A, Akouété B, Yaovi JE, Ekoué D, Atsi W, Assang D. Tension band wiring fixation is associated with good functional outcome after Olecranon fracture at Togo Hospital. Annals Afr Surg. 2011;8:154-9.

\begin{tabular}{|c|c|c|c|}
\hline Article received on: $27 / 03 / 2012$ & Accepted for Publication: & 30/05/2012 & Received after proof reading: $\quad 00 / 00 / 0000$ \\
\hline $\begin{array}{l}\text { Correspondence Address: } \\
\text { Dr Muhammad Inam } \\
\text { Department of Orthopedic and Spine Surgery } \\
\text { PGMI Hayatabad Medical Complex Peshawar } \\
\text { dr_mohammadinam@yahoo.co.uk }\end{array}$ & & & $\begin{array}{l}\text { Article Citation: } \\
\text { Inam M, Satar A, Hassan W, Saeed M, Arif M. Olecranon } \\
\text { fracture. Professional Med JAug 2012;19(4): 537-541. }\end{array}$ \\
\hline
\end{tabular}

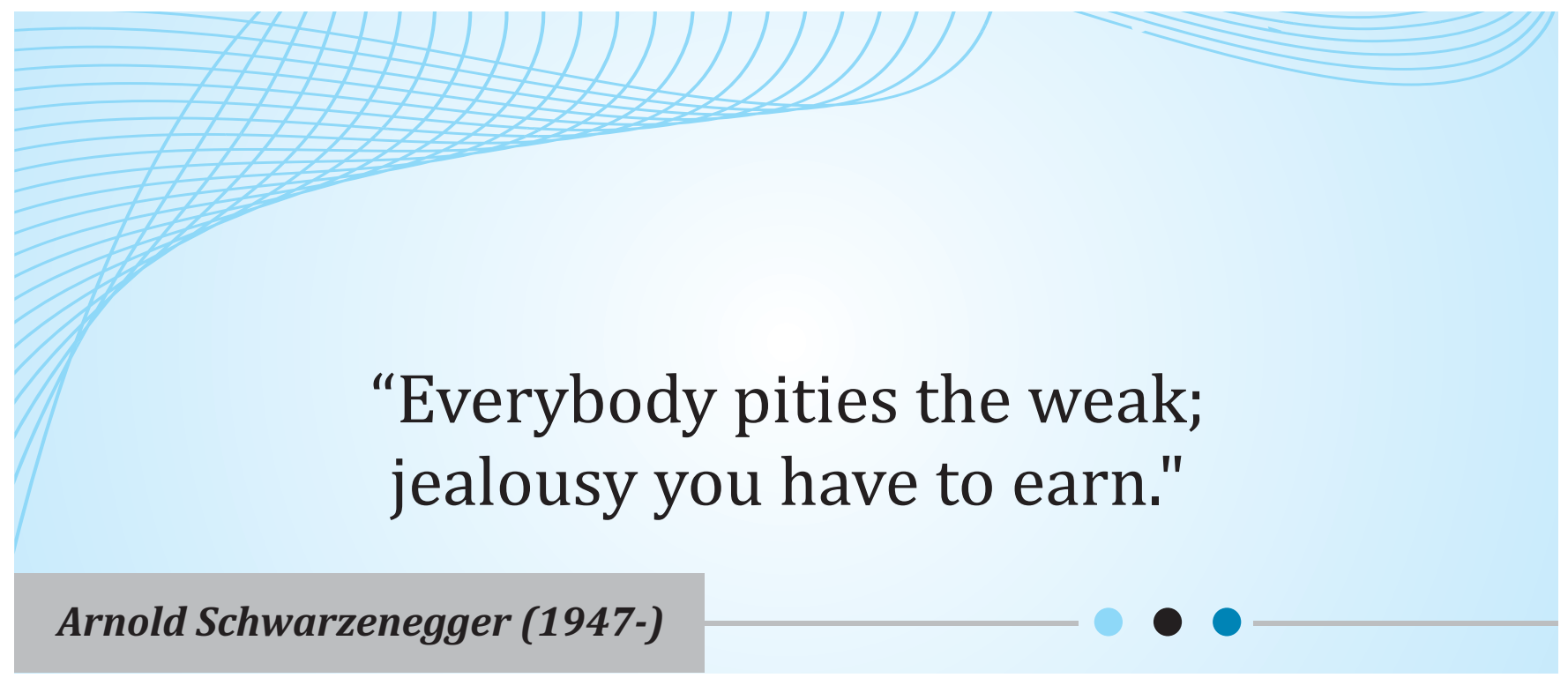

